\title{
The Use of ICT to Support Students with Dyslexia
}

\author{
Nadia Diraä, Jan Engelen, Pol Ghesquière, and Koen Neyens \\ K.U. Leuven - Belgium \\ \{Nadia.Diraa, Jan. Engelen\} @esat.kuleuven. be, \\ Pol.Ghesquiere@ped.kuleuven.be, Koen.Neyens@dsv.kuleuven.be
}

\begin{abstract}
The Katholieke Universiteit Leuven (K.U.Leuven) has a tradition of supporting students with a disability in order to guarantee equal opportunities to achieve their educational, personal and vocational goals. The K.U.Leuven policy is working towards inclusive education in the long term, by improving facilities and accommodation for certain target groups in the short term. Efforts have also been directed to make the learning environment more accessible for all kind of students, especially over the last few years. One of the target groups that has increasing numbers are students with learning disabilities (including dyslexia, dyscalculia, ...). To accommodate these students, the K.U.Leuven set off a project to evaluate the use of assistive technology (AT) for dyslexia. This small-scale study examined the experiences of two groups of students with dyslexia using 2 different software programs specifically developed to support this group of students. It was apparent that for students with dyslexia, reading and studying presents additional limitations which AT could facilitate to some extent.
\end{abstract}

Keywords: People with disabilities, Dyslexia, Assistive Technology, Accessibility.

\section{Introduction}

Dyslexia is a disorder in which a persistent problem arises with acquiring and applying reading and/or spelling at word level [1]. At this moment, there are growing numbers of students with dyslexia accessing higher education. At the K.U.Leuven, we have seen a yearly increase up to $20 \%$ of students with a learning disability since 2005-2006. Students with a learning disability like dyslexia now account for $41 \%$ of the students with a disability. In the Netherlands, about 14.000 out of 500.000 students have dyslexia; this is $3 \%$ of the total student population [2]. The same evolution is seen in the UK where the population of students with dyslexia has risen from 21.000 in $2004 / 2005(2.4 \%)$ to $27.465(3.1 \%)$ in $2007 / 2008$ [3]. At the same time we see that evolutions in Internet and Communication Technologies (ICT) have created a lot of possibilities to prevent "handicap situations" (meaning a reduced accomplishment of life habits as a result of complex interactions between personal factors (personal characteristics such as impairments) and environmental factors) [4]. There are some studies demonstrating statistically significant impact of the use of a text reader on student text comprehension [5] [6].

In the period 2008-2009 knowledge and expertise in relation to accessibility of the digital learning environment and the use of ICT support within the K.U.Leuven has 
been brought together and the support of several internal K.U.Leuven services has been started [7]. The digitalisation of the educational process that used to be an obstacle for students with impairments therefore now becomes a facilitating process and a real support for them. K.U.Leuven's Working Group on Digital Accessibility [8] has stimulated this project from an inclusive vision on the process of digital learning support. To address the needs of students with dyslexia, this project aimed to evaluate the effects of a campus wide introduction of AT for dyslexia.

\section{Methodology}

\subsection{Special-Purpose Software}

Students with special needs, especially dyslexia, are accommodated by the use of AT. For dyslexia, there are 2 software programs distributed in primary and secondary education in Flanders. These programs are also being used by students in higher education. At the start of this project, there were no numbers available about the number of students with dyslexia using AT. Since these programs became more and more popular among students, the Working Group on Digital Accessibility asked for funding to do some small-scale research on the application of ICT to facilitate students with dyslexia.

These AT consist of Kurzweil3000 and Sprint. Kurzweil3000 [9] is a comprehensive reading, writing and learning software solution for students with special needs. The software can access documents in print (with the use of a scanner) or on the web, and electronic documents. Students can use it to read course material with increased speed; they can get visual and auditory feedback and use it for writing assignments.

Sprint [10] adds speech and language technology to a computer so that students can listen to documents, internet pages, email,... in fact to any available text on their computer, as Sprint reads them out loud. Sprint also can read aloud while text is being entered which helps in detecting mistakes.

This part describes how AT has been introduced to students with dyslexia at the K.U.Leuven. At the start of the academic year, the Disability Team of the K.U.Leuven organised an information session about assistive technology for students with dyslexia. This introduction was given by a remedial teacher. About 40 students with dyslexia were present. At the end of this session, the Disability Team made an appeal to participate in a small-scale research with two software programs for dyslexia: Kurzweil3000NL and Sprint. Kurzweil3000NL is a text reader with embedded study and writing skills localized for the Dutch language. It supports students with special needs by making it possible to access almost any document. Sprint is a comparable program that adds speech and language technology to a computer [10]. Both firms, Sensotec [11] and Jabbla [12], agreed to put the software at the disposal of the participating students for free in return for feedback.

There were about 40 students present at the information session, out of which 25 applied for participation in the study. Afterwards there were some more students who wanted to participate. They were also invited to the introductory sessions for each software program. Subsequently, introductory sessions were organised for the 2 different software programs. These introductions were given by trainers provided by the companies. At these sessions, the students were given the software program either on a usb stick (Sprint, 15 students) or on cd (Kurzweil3000, 17 students). 
Table 1. Research Participants

\begin{tabular}{|c|c|c|c|c|}
\hline Course & $\mathrm{M} / \mathrm{F}$ & year of birth & Program & AT experience \\
\hline Engineering & $\mathrm{M}$ & 1981 & Sprint & Yes \\
\hline Engineering & $\mathrm{F}$ & 1988 & KW3000 & N/A \\
\hline Engineering & $\mathrm{F}$ & 1990 & KW3000 & Yes \\
\hline Computer Science & M & 1987 & KW3000 & Yes \\
\hline Geography & $\mathrm{F}$ & 1988 & KW3000 & Yes \\
\hline Geology & $\mathrm{F}$ & 1986 & SPRINT & No \\
\hline Pharmaceutical Sciences & $\mathrm{F}$ & 1988 & SPRINT & No \\
\hline Biology & $\mathrm{F}$ & N/A & SPRINT & N/A \\
\hline Physiotherapy & M & 1990 & SPRINT & No \\
\hline Rehabilitation Sciences & $\mathrm{F}$ & N/A & KW3000 & N/A \\
\hline Rehabilitation Sciences & $\mathrm{F}$ & N/A & KW3000 & N/A \\
\hline Political Sciences & $\mathrm{F}$ & 1988 & SPRINT & Yes \\
\hline Law & $\mathrm{F}$ & 1987 & KW3000 & N/A \\
\hline Law & M & 1986 & SPRINT & Yes \\
\hline Business Economics & $\mathrm{F}$ & 1989 & SPRINT & No \\
\hline History & $\mathrm{F}$ & 1990 & KW3000 & No \\
\hline History & M & 1988 & KW3000 & No \\
\hline Anthropology & M & N/A & SPRINT & N/A \\
\hline Educational Sciences & $\mathrm{F}$ & 1985 & KW3000 & No \\
\hline Educational Sciences & $\mathrm{F}$ & 1987 & KW3000 & No \\
\hline Educational Sciences & $\mathrm{F}$ & 1978 & SPRINT & No \\
\hline Educational Sciences & $\mathrm{F}$ & 1990 & SPRINT & No \\
\hline Educational Sciences & $\mathrm{F}$ & 1989 & KW3000 & No \\
\hline Educational Sciences & $\mathrm{F}$ & 1986 & SPRINT & No \\
\hline Educational Sciences & $\mathrm{M}$ & 1976 & KW3000 & No \\
\hline Psychology & $\mathrm{F}$ & 1987 & KW3000 & No \\
\hline Psychology & $\mathrm{F}$ & 1986 & SPRINT & No \\
\hline Psychology & $\mathrm{F}$ & 1979 & KW3000 & N/A \\
\hline Psychology & $\mathrm{F}$ & 1989 & KW3000 & Yes \\
\hline Psychology & $\mathrm{F}$ & 1971 & KW3000 & No \\
\hline Psychology & $\mathrm{F}$ & 1990 & SPRINT & No \\
\hline Sexuality Studies & $\mathrm{F}$ & 1987 & SPRINT & No \\
\hline Total: & $F: 25$ & & KW3000: 17 & Yes: 7 \\
\hline 32 participants & M: 7 & & SPRINT: 15 & No: 18 \\
\hline
\end{tabular}

\subsection{Survey}

All participants agreed to be interviewed 3 times during the academic year. The starting interview focused on their experience with ICT and their diagnosis of dyslexia. A second interview was held just after the first semester examinations and it focused on the possibilities of the AT, the problems and needs the students have faced, usability, and possible improvements. Finally, at the end of the academic year but before the June examinations, an evaluation of the project by the students was held.

\subsubsection{First Survey}

These semi-structured interviews were done by 2 master students in Educational Sciences. The first interviews consisted of 2 parts: one about the impact of dyslexia on 
their life, and one on the use and experience the participants have with ICT and AT in particular. On average, the students were satisfied by the, still growing, support from the Disability Team. The main problem is situated in the communication with teachers and teaching assistants especially during assessments. Many students find it difficult to disclose their disability to get digital course material. Another aspect is the lack of a generally accepted format for attesting dyslexia. At this moment, students with a disability are asked to provide (medical) documentation or attestation [13] for verification. The students also don't have a clear view on what to expect about reasonable adjustments and their rights. It seems that every faculty at the K.U.Leuven has some kind of support but there is not yet a single policy across the university. As a result of these interviews, additional training was provided for Kurzweil3000. The users of Sprint didn't indicate this need. Some students formulated reserves for using the software. They didn't want to become too dependent on it if they aren't sure they can continue to use the software for the full length of their education.

\subsubsection{Second Survey}

The second interview focused on the installation and use of ICT and the AT for dyslexia, on the accessibility of digital course material and on the drop outs. The installation of Kurzweil3000 proved to be rather difficult. The students started with demoversions which had to be removed from the computers before the final version could be installed. This resulted in the fact that after the demo-versions expired, only 6 out of 17 participants managed to install the new version without encountering any problems. However, not all these problems were due to the software. Some students had e.g. hardware that was not fit or had a broken cd-player. For Sprint, this was not an issue since the program was delivered on a usb stick which could be used on any computer with Windows installed. Most students used the AT to read course material on a higher speed than without. Some made mp3 files to listen to during other activities. Also the possibility to highlight in the electronic version of the text was found a plus. Negative aspects were the impossibility for the program to transpose mathematical and scientific formulae to speech, preparing files for text-to-speech could take some time, files needing to be divided in chapters no longer than 40 pages otherwise the program wouldn't load them. The availability of digital course material was another important issue. Some teachers have reservations towards putting to disposal digital versions of their course material. To counter this all students received a letter stating that they participated in a research project, with a signed agreement not to distribute any material given to them as part of this project. Some students felt uncomfortable to disclose their disability to get the digital course material. To meet further needs for electronic versions, the Disability Team set up a scan service for students with dyslexia. Here the students could scan the courses they wanted to study with the AT. Twice a week, this service was available for students during lunch hours. About 15 participants used the service to scan and prepare documents using the scanner and OCR. Also other students with dyslexia using AT, but not participating in the research project, made use of the scan service. At this phase of the study about 8 participants didn't use the program at all. Asked for the reasons, 4 still had problems installing Kurzweil3000. Others didn't want to invest too much time in acquiring the skills needed to make use of AT. Or they didn't want to participate in the interviews. 


\subsubsection{Final Survey}

The final survey took place before the examinations in June 2009. Here we present only preliminary results since all the data haven't been studied in detail yet. This last interview focused on the use of the program, an evaluation and some remarks and feedback about the software programs. At that moment there were 10 participants out of 18 still using Kurzweil3000 and 11 out of 15 participants still using Sprint. Most participants only use the AT for text-to-speech assistance with reading. Some made efforts to improve their knowledge about the program but this is a minority. Furthermore, they didn't express interest in additional training to get a more profound knowledge of the AT. Negative aspects students expressed are: the time needed for scanning course material, problems acquiring digital material and the time needed to prepare this material for use with AT. They suggested filing digital course material in some kind of central repository for future use by other dyslexic students (which we plan for early 2010). Also they didn't find good use in the possibilities these software packages present for highlighting and structuring text, and creating outlines, word lists or study guides.

\section{Conclusions}

During the academic year 2008-2009, 32 students participated in a small-scale research on the use of AT for students with dyslexia. Both Kurzweil3000 and Sprint showed advantages and disadvantages. Students need to have some basic computer skills to be capable of using either software. There is a clear need for sufficient training to make fully use of all the possibilities this AT offers. Also other preconditions need to be in place to successfully implement this software. These preconditions consist of the availability of digital course material, the possibility/authorization to use ICT during courses and assessments, and sufficient computer skills for the students. As can be concluded from the survey, some participants dropped out of the research due to the lack of digital course material. They found that scanning all their readers and handbooks would take too much time since they are already limited in time due to their disability. The advantage of the AT, i.e. the possibility to read at higher speed didn't countervail the time they anticipated needing for scanning all material. With the further implementation of AT for dyslexia, K.U.Leuven needs to provide sufficient access to digital course material. Another precondition is the possibility to use ICT during courses and assessments. The use of ICT during courses didn't cause many conflicts. However, the use during assessments presented some problems. Some teachers didn't want students to use their own laptops or didn't want them to use any ICT at all. To counter the first problem, the Disability Team provided several clean laptops with the AT technology pre-installed. Another problem was the use of highlighted electronic documents. Some assessments allowed students to bring course material to examination but not all students with dyslexia were allowed to use their electronic documents. The possibility to use a function like "Find" in an electronic version would give them a remarkable speed advantage with regard to other students. The AT Kurzweil3000 has the facility to disable some functions and can keep a record of actions taken while using the program. Some faculties chose to prepare audio versions of the exams and $\mathrm{mp} 3$ players were put at disposal for students with reading 
impairments. A last but not at all the least precondition for success are the computer skills of the students. Most used a pc or laptop with Windows Vista or XP. Considering the amount of problems encountered while installing AT, most students needed assistance with this. There also needs to be sufficient training in the software programs to make sure the students understand the full capabilities of these AT.

\section{References}

1. van Dyslexie, D.: Brochure Stichting Dyslexie Nederland. Revised edn. (2003)

2. Broenink, N., et al.: Studeren met een handicap, p. 25. Verwey-Jonker Instituut (2001)

3. Higher Education Statistics Agency, Students and Qualifiers Data Tables, http://www.hesa.ac.uk/index.php/component/option, com_datatables/Itemid, 121/task, show_category/catdex, 3 /\#disab (accessed 10/07/09)

4. Fougeyrollas, P.: Québec: Cqcidih/Sscdih (1995b)

5. Dimmitt, S., Hodapp, J., Judas, C., Munn, C., Rachow, C.: Iowa Text Reader Project Impacts Student Achievement. Closing the Gap 24(6), 12-13 (2006)

6. Draffan, E.A., Evans, D.G., Blenkhorn, P.: Use of assistive technology by students with dyslexia in post-secondary education. Disability and Rehabilitation: Assistive Technology 2(2), 105-116 (2006)

7. OOP project, Verhoogde toegankelijkheid van onderwijsgerichte ICT toepassingen voor personen met een functiebeperking (K.U.Leuven funded project, 2006)

8. K.U.Leuven Working Group on Digital Accessibility, http://www.kuleuven.be/ digitaletoegankelijkheid/werkgroep.html

9. Kurzweil3000, http: / /www. kesi.com/kurz3000.aspx (accessed 10/07/09)

10. Sprint,

http: / /www.jabbla.com/software/products.asp?

$\mathrm{Lid}=4 \&$ pnav $=; 2 ; \&$ item=11\&lang=en (accessed 10/07/09)

11. Sensotec NV, http://Www.sensotec.be/dyslexie/Producten/K3000/ Default.aspx

12. Jabbla, http: //www.jabbla.com

13. K.U.Leuven Disability Team, http://www.kuleuven.be/studentservices/ disability.html (accessed 10/07/09) 